\title{
ASISTENCIA TÉCNICA DURANTE LA CONSTRUCCIÓN DE PLATAFORMAS Y TALUDES PARA LA ADECUACIÓN DEL BOTADERO SAN LUIS Y PARA EL DISEÑO DE UNA TRINCHERA PARA EL MANEJO TEMPORAL DE RESIDUOS SÓLIDOS MUNICIPALES EN EL BOTADERO DE SAN LUIS, DISTRITO DE PISCO, PROVINCIA DE PISCO, DEPARTAMENTO DE ICA
}

\author{
Huiman Cruz, Alberto
}

\section{INTRODUCCIÓN}

El 15 de agosto de 2007, la zona sur del Perú sufrió un sismo de 7.9 grados en la escala de Ritcher, cuyo epicentro estuvo frente a Pisco, ocasionando un colapso en la mayoría de las edificaciones y de los servicios del manejo de residuos sólidos con que contaba la ciudad. Pisco no cuenta con un relleno sanitario para la disposición final de los residuos sólidos esta se viene realizando en un botadero denominado San Luis.

Al encontrarnos ante una situación de emergencia y para evitar una propagación de vectores, CONAM realiza una convocatoria para tomar la mejor decisión, esta fue: crear un botadero controlado.

\section{OBJETIVOS}

- Proporcionar asistencia técnica durante la construcción de plataformas y taludes en el botadero San Luis, para disponer los escombros.

- Diseñar la Plataforma para el enterramiento de los residuos sólidos, utilizando los métodos de ingeniería de los rellenos sanitarios durante tres meses.

\section{MATERIALES Y MÉTODOS}

Los materiales de ayuda fueron:

Temático: Perfil y el Expediente Técnico de Clausura del Botadero de San Luis.

De dibujo y edición: Software's: autocad y del paquete de Microsoft office.

El método empleado fue el siguiente:

Se asesoró a los funcionarios municipales para que lleven a cabo el acondicionamiento de residuos sólidos existentes en el botadero de San Luis, de la siguiente manera:

- Remover los residuos sólidos existentes de tal forma que tenga una cota final definida, para que encima de ellos se extienda los residuos de escombros.

- Triturar con el peso del tractor sobre oruga los escombros que en su mayoría eran de adobe.

- Acondicionar vías internas para una mejor facilidad del ingreso de los camiones volquetes que transportaban los residuos.

- $\quad$ El reacomodo de los residuos sólidos, respetando los 20 metros que tiene como ancho de dominio de la vía vecinal existente.

- Acondicionar el área de los residuos sólidos existente en una plataforma de las siguientes dimensiones:
Largo $=150 \mathrm{~m}$, ancho $=50 \mathrm{~m}$, altura $=2.35$ metros, $\mathrm{y}$ talud de $\mathrm{H} / \mathrm{V}: 3 / 1$.

- Después de culminado el proceso de clausura, acondicionar las chimeneas en toda el área con un radio de 40 metros entre sí.

- Para una mejor disposición final de los residuos de escombros de parte de los camiones volqueteros; se recomendó acondicionar rampas de acceso cada 50 metros de separación entre ellos.

- Se recomendó mejorar la vía de acceso para un mejor tránsito de los camiones recolectores.

Se diseñó el método mas acorde para la disposición final de residuos, para ello se consideró que los planos elaborados contengan:

\section{Habilitación de Plataformas:}

- Construcciones en Plataformas (Explanaciones, Construcción de Drenes de Lixiviado, Construcción de Chimeneas)

- Construcción de la Poza de Almacenamiento de Lixiviado.

Operación Diaria de Enterramiento de los Residuos Sólidos en Plataformas

- Conformación de Plataforma (Apilación y Carguío del Material de Cobertura, Transporte del Material de Cobertura, Esparcido y Compactación del Material de Cobertura, y Esparcido y Compactación de los Desechos Sólidos).

- Instalación de Quemadores

\section{RESULTADOS}

- $\quad$ El botadero se encuentra ubicado en la Localidad de San Luis, Distrito de Pisco, Provincia de Pisco, Departamento de Pisco

- Actualmente ocupa un área de 5.9 ha y un perímetro de $1074.8 \mathrm{~m}$.

- La población considerada para el diseño de la plataforma es la suma del distrito de Pisco (70 996) y San Andrés (16 923): 87919 habitantes.

- La generación per cápita del distrito de Pisco es 0.61 kg/hab./día y en San Andrés es 0.74 kg/hab./día, haciendo un promedio de: $0.68 \mathrm{~kg} / \mathrm{hab} . / \mathrm{día}$.

- La generación de residuos sólidos domiciliarios para el lapso de tres meses es de $13989.67 \mathrm{~m}^{3}$.

- En función de la topografía se eligió como método el de área, para una vida útil de tres meses. 
- El diseño incluye la colocación de geomembrana para la impermeabilización del suelo, evitando la filtración de los lixiviados.

- $\quad$ El diseño de los drenes de lixiviados está en función de la cantidad de lixiviado que se producirá y la profundidad (el ancho del dren está acondicionado a los $60 \mathrm{~cm}$ del ancho de chimenea).

- Se diseñó la construcción de una poza de almacenamiento de lixiviado de las siguientes dimensiones: Largo $=11.00 \mathrm{~m}$, ancho $=11.00 \mathrm{~m}, \mathrm{y}$ profundidad $=1.00 \mathrm{~m}$.

\section{DISCUSIÓN}

La visita de campo y la topografía del terreno, permitió determinar que la medida mas acorde para la adecuación del botadero era utilizar el método de área, además el construir trincheras resultaba costoso e innecesario 8para una vida útil de tres meses), por ello se propuso que una plataforma grande era lo que Pisco requería para atender los residuos municipales y los escombros resultantes luego del sismo.

El presupuesto de la etapa de habilitación se detalla en el cuadro $\mathrm{N}^{\circ} 01$, y el presupuesto de operación en el cuadro $\mathrm{N}^{\circ} 02$.

\section{Cuadro № 01: Presupuesto de la etapa de habilitación}

\begin{tabular}{|l|r|}
\hline \multicolumn{1}{|c|}{ Presupuesto Habilitación } & Valores en Sl. \\
\hline Costo Directo: & \\
- Mano de obra & 93372.84 \\
- Materiales & 121375.69 \\
- Equipos & 143593.55 \\
- Gastos generales & 27040.14 \\
- Utilidad 5\% & 17917.10 \\
- Sub total & $403,299.33$ \\
- IGV 19\% & $76,626.87$ \\
\hline \multicolumn{2}{|c|}{ Total } \\
\hline
\end{tabular}

Fuente: Elaboración propia (costos al 31 de octubre de 2007).

Cuadro № 02: Presupuesto de la etapa de operación.

\begin{tabular}{|c|c|}
\hline Presupuesto Habilitación & Valores en Sl. \\
\hline $\begin{array}{l}\text { - Operación diaria de enterramiento } \\
\text { de los residuos sólidos } \\
\text { - Conformación de plataformas } \\
\text { - Apilación y carguío de material de } \\
\text { cobertura } \\
\text { - Transporte y descarga del material } \\
\text { de cobertura } \\
\text { - Esparcido y compactación de } \\
\text { material de cobertura } \\
\text { - Esparcido y compactación de los } \\
\text { residuos sólidos } \\
\text { - Instalación de quemadores } \\
\text { - Quemadores de gases } \\
\text { - Costo directo } \\
\text { - Gastos generales } 7.5459 \% \\
\text { - Utilidad } 5 \% \\
\text { - Sub total } \\
\text { - IGV } 19 \%\end{array}$ & $\begin{array}{r}127,032.77 \\
126,792.20 \\
7,465.04 \\
92,901.49 \\
\\
5,080.77 \\
\\
21,344.90 \\
240.57 \\
240.57 \\
127,032.77 \\
9,585.77 \\
6,351.64 \\
142,970.18 \\
27,164.33\end{array}$ \\
\hline Total & $170,134.51$ \\
\hline
\end{tabular}

Fuente: elaboración propia (costos al 31 de octubre de 2007).

\section{CONCLUSIONES}

- La decisión de construir un botadero controlado garantiza no solo una adecuada práctica de disposición de residuos ante la situación de emergencia de lugar, permite también el planeamiento local para la búsqueda de medidas ingenieriles duraderas que garanticen un sistema sostenible de disposición de residuos.

- La asistencia técnica proporcionada permitió aprovechar al máximo los residuos dispuestos, así el $20 \%$ del material de cobertura utilizado provenía de los escombros a dispones.

- Para lograr controlar la posible propagación de vectores transmisores de enfermedades en la población afectada por el sismo, se sugirió que la mejor manera de garantizar el manejo de residuos sólidos era tratar al botadero existente como relleno sanitario, por ello pese a ser un botadero, se hicieron una serie de recomendaciones para que su tratamiento interno sea tipo relleno durante los tres meses calculados de existencia.

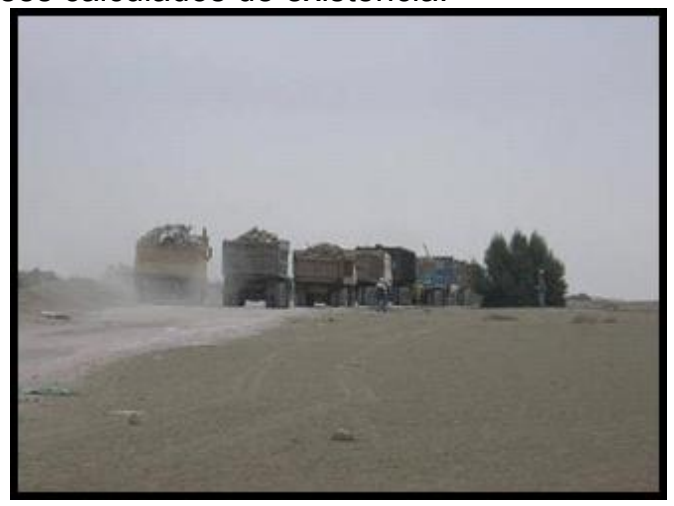

Fotografía № 01: Transporte de escombros hacia el botadero, mediante el uso de volquetes.

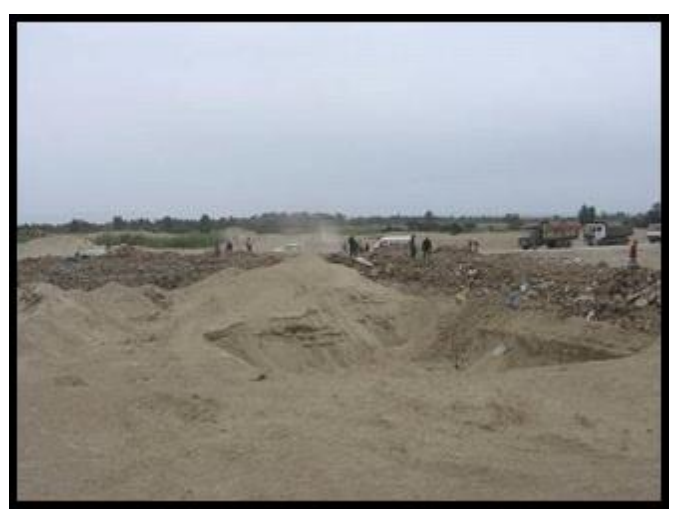

Fotografía № 02: Material de escombro dispuesto en el botadero conformando los terraplenes finales.

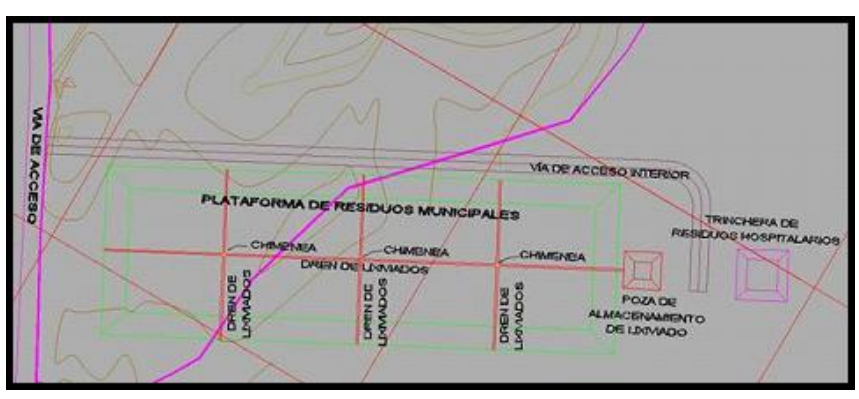

Figura № 01: Distribución de estructuras en el Botadero San Luis 